\title{
The PDE5 inhibitor vardenafil does not affect auditory sensory gating in rats and humans
}

Citation for published version (APA):

Reneerkens, O. A. H., Sambeth, A., van Duinen, M. A., Blokland, A., Steinbusch, H. W. M., \& Prickaerts, J. (2013). The PDE5 inhibitor vardenafil does not affect auditory sensory gating in rats and humans. Psychopharmacology, 225(2), 303-312. https://doi.org/10.1007/s00213-012-2817-7

Document status and date:

Published: 01/01/2013

DOI:

10.1007/s00213-012-2817-7

Document Version:

Publisher's PDF, also known as Version of record

Document license:

Taverne

\section{Please check the document version of this publication:}

- A submitted manuscript is the version of the article upon submission and before peer-review. There can be important differences between the submitted version and the official published version of record.

People interested in the research are advised to contact the author for the final version of the publication, or visit the DOI to the publisher's website.

- The final author version and the galley proof are versions of the publication after peer review.

- The final published version features the final layout of the paper including the volume, issue and page numbers.

Link to publication

\footnotetext{
General rights Owners
rights.

- You may freely distribute the URL identifying the publication in the public portal. please follow below link for the End User Agreement:

www.umlib.nl/taverne-license

Take down policy

If you believe that this document breaches copyright please contact us at:

repository@maastrichtuniversity.nl

providing details and we will investigate your claim.
}

Copyright and moral rights for the publications made accessible in the public portal are retained by the authors and/or other copyright owners and it is a condition of accessing publications that users recognise and abide by the legal requirements associated with these

- Users may download and print one copy of any publication from the public portal for the purpose of private study or research.

- You may not further distribute the material or use it for any profit-making activity or commercial gain

If the publication is distributed under the terms of Article $25 \mathrm{fa}$ of the Dutch Copyright Act, indicated by the "Taverne" license above, 


\title{
The PDE5 inhibitor vardenafil does not affect auditory sensory gating in rats and humans
}

\author{
O. A. H. Reneerkens - A. Sambeth - M. A. Van Duinen • \\ A. Blokland $\cdot$ H. W. M. Steinbusch • J. Prickaerts
}

Received: 6 April 2012 / Accepted: 16 July 2012/Published online: 2 August 2012

(C) Springer-Verlag 2012

\begin{abstract}
Rationale Sensory gating is an adaptive mechanism of the brain to prevent overstimulation. Patients suffering from clinical disorders such as Alzheimer's disease or schizophrenia exhibit a deficit in gating, which indicates not only an impairment in basic information processing that might contribute to the cognitive problems seen in these patients. Phosphodiesterase type 5 inhibitors (PDE5-Is) have been shown to improve cognition in rodents in various behavioural tasks and might consequently be an interesting target for cognition enhancement. However, the effects of PDE5-Is on sensory gating are not known yet.

Objectives This work aims to study the effects of PDE5 inhibition on auditory sensory gating in rats and humans. Methods In the rat study, vehicle or $0.3-3 \mathrm{mg} / \mathrm{kg}$ of the PDE5-I vardenafil was given orally $30 \mathrm{~min}$ before testing and electrode locations were the vertex, hippocampus and the striatum. The human subjects received placebo, 10$20 \mathrm{mg}$ vardenafil $85 \mathrm{~min}$ before testing and sensory gating was measured at the cortex $(\mathrm{Fz}, \mathrm{Fcz}$ and $\mathrm{Cz})$ electrodes. Results Significant gating was only found for the N1 component in rats while all three peaks P1, N1 and P2 showed
\end{abstract}

O. A. H. Reneerkens · M. A. Van Duinen · H. W. M. Steinbusch •

J. Prickaerts

Department of Psychiatry and Neuropsychology, School for

Mental Health and Neuroscience, Maastricht University,

Maastricht, The Netherlands

A. Sambeth $\cdot$ A. Blokland

Department of Neuropsychology and Psychopharmacology,

Maastricht University,

Maastricht, The Netherlands

O. A. H. Reneerkens - A. Sambeth - M. A. Van Duinen •

A. Blokland $\cdot$ H. W. M. Steinbusch · J. Prickaerts $(\square)$

European Graduate School of Neuroscience (EURON),

Maastricht University,

P.O. Box 616, 6200 MD Maastricht, The Netherlands

e-mail: jos.prickaerts@maastrichtuniversity.nl gating in humans, i.e. the response to the second sound click was decreased as compared with the first for these deflections. Administration of vardenafil did neither have an effect on sensory gating in rats nor in humans.

Conclusions These findings imply that positive effects of PDE5 inhibition on cognition are not mediated by more early phases of information processing.

Keywords Sensory gating · Translational · PDE5 . Vardenafil $\cdot$ Basic auditory information processing $\cdot$ EEG

\section{Introduction}

Sensory gating is an automatic process involved in information processing. More specifically, it is an adaptive mechanism of the central nervous system that prevents overstimulation of higher cortical areas and helps filtering sensory information (e.g. Cromwell et al. 2008). The standard paradigm assessing this mechanism consists of two identical auditory stimuli that are presented with an interstimulus interval (ISI) between 0.5 and $2 \mathrm{~s}$ and an intertrial interval (ITI) of at least $8 \mathrm{~s}$ (Cromwell et al. 2008; Hajos 2006). In healthy individuals - humans as well as animalsthe response to the second stimulus (S2) will be smaller than the response to the first stimulus (S1). Of note, the duration of the ISI is crucial; if it is shorter than $0.5 \mathrm{~s}$ or longer than $2 \mathrm{~s}$, sensory gating will not be elicited. Extensive research has shown that the process of sensory gating is disrupted in patients suffering from clinical disorders including schizophrenia and Alzheimer's disease (e.g. Adler et al. 1982; Ally et al. 2006; Javitt 2009; Jessen et al. 2001).

The responses evoked by this auditory sensory gating paradigm can be assessed using electroencephalographic (EEG) and event-related potential (ERP) measurements. In humans, the P50, also known as P1, is considered to be the main ERP component related to sensory gating (e.g. Chang 
et al. 2011; Dalecki et al. 2011). In addition, the N100 (N1) and P200 (P2) might also be affected (e.g. Boutros et al. 2009; Lijffijt et al. 2009). There is still a debate about which ERP component in rats is possibly the functional equivalent of the P50 in humans. Some researchers suggest that the P13 (P1) (e.g. Miyazato et al. 1999) is the most suitable candidate, whereas others assume it is the N40 (N1) or P60 (P2) (e.g. Mears et al. 2006; Zhou et al. 2008). It has also been suggested that the entire P1-N1-P2 complex is involved in the auditory sensory gating paradigm in rats just as in humans (e.g. Broberg et al. 2010; Mears et al. 2009).

Recently, phosphodiesterases (PDEs) gained increased attention as a promising target for cognition enhancement. Depending on the enzyme subclass, they selectively hydrolyze the second messengers cyclic adenosine monophosphate (cAMP) and/or cyclic guanosine monophosphate (cGMP) (Bender and Beavo 2006). It has been shown that drugs that prevent the breakdown of these PDEs, the socalled PDE inhibitors (PDE-Is), improve cognition in animals in a wide range of behavioural tasks (for review, see Reneerkens et al. 2009). Since the cGMP-specific phosphodiesterase type 5 inhibitors (PDE5-Is) are clinically approved for treatment of erectile dysfunction, they can be tested in animals as well as humans, which makes them particularly interesting from a translational perspective. It has already been shown that PDE5 inhibition has a positive effect on a variety of cognitive processes in animals, including learning (e.g. Devan et al. 2006, 2007), memory (e.g. Prickaerts et al. 2002b; Reneerkens et al. 2012; Rutten et al. 2007; van Donkelaar et al. 2008), executive functioning and response inhibition (Rutten et al. 2008). In contrast, only a limited number of studies investigated the effects of PDE5Is on cognition in humans. Three of those studies did not show any effects of PDE5 inhibition on cognitive performance in healthy adults (Grass et al. 2001; Schultheiss et al. 2001) and patients with schizophrenia (Goff et al. 2009) respectively. Yet, EEG measurements in healthy adults indicated that there might be an effect of treatment with the PDE5-I sildenafil on attention (Schultheiss et al. 2001). Interestingly, it has recently been demonstrated that repeated dosing of the PDE5-I Udenafil improves the cognitive performance of patients suffering from a erectile dysfunction on a modified version of the mini-mental state examination and an assessment battery addressing frontal executive functioning (Shim et al. 2011).

In our present study, we investigated the effects of PDE5 inhibition on sensory gating in rats and humans. Rats were included because of the extensive learning- and memoryenhancing effects that have already been reported in rodents while to our knowledge basic auditory information processing has not been studied yet after PDE5 inhibition. Likewise, the effects on sensory gating in humans were studied to gain further insight into the effects of PDE5 inhibition on information processing in humans, but also to see whether the drug effects found in rodents can be translated to the human situation and vice versa. It has indeed been shown that the ERPs of humans and rats show a substantial amount of similarities (e.g. Sambeth et al. 2003). Based on these findings, we expect that the effects of drugs on these ERPs are comparable between humans and animals (Maxwell et al. 2004). First, we tested whether our paradigm elicited sensory gating. Next, the effects of the PDE5-I vardenafil on sensory gating were investigated. It was chosen to test $0.3-3 \mathrm{mg} / \mathrm{kg}$ vardenafil in rats since this dose range is mostly used in a wide array of behavioural tasks (e.g. Prickaerts et al. 2004, 2002b; Reneerkens et al. 2012; Rutten et al. 2007, 2009). We included the vertex, hippocampus and striatum as electrode locations because of their involvement in sensory gating. The vertex was chosen to represent the cortex since the EEG signal at this location is relatively comparable to that at a similar location in humans. We recorded EEG from the Fz, Fcz and $\mathrm{Cz}$ (vertex) locations in humans (see Jasper 1958) and used 10 and $20 \mathrm{mg}$ because these are the dosages commonly used in humans.

\section{Materials and methods}

Animal study

\section{Animals}

All experimental procedures were approved by the local ethical committee for animal experiments of Maastricht University and met governmental guidelines. Thirteen 3month-old male Wistar rats (Harlan, The Netherlands) were used with average body weights of $385 \mathrm{~g}( \pm 12.50)$. The animals were housed individually in standard Makrolon cages on sawdust bedding in an air-conditioned room (about $20{ }^{\circ} \mathrm{C}$ ). They were kept on a 12/12-h reversed light/dark cycle (lights on from 1900 to 0700 hours) and had free access to food and water. The rats were housed in the same room as where they were tested. All testing was done between 0900 and 1800 hours in a shielded Skinner box.

\section{Surgery and EEG recordings}

The animals received $0.1 \mathrm{ml} / \mathrm{kg}$ Temgesic (Schering-Plough B.V., Utrecht, The Netherlands) subcutaneously $30 \mathrm{~min}$ before surgery as analgesia. Forene isoflurane (Abbott B.V., Hoofddorp, The Netherlands) was used as a general inhalation anaesthetic. After the animal was placed into the stereotactic apparatus and an incision was made to expose the skull, lidocaine was applied as additional local anaesthesia. Next, bregma was identified and the electrodes were placed in the striatum (AP, 0.48; ML, -3.0 ; and DV, -5.0 ), dorsal 
hippocampus (AP, -2.8 ; ML, -1.8 ; and $\mathrm{DV},-2.6$ ) and vertex (AP, -3.5 ; ML, -1.0 ; and DV, -1.0) (Paxinos and Watson 1998). The reference and ground electrodes were both placed in the cerebellum. The electrodes and the connector were fixed to the skull by using three screws and Paladur denture acrylic (Heraeus Kulzer, Hanau, Germany). The animals were given at least 2 weeks to recover from the surgery.

In the first week after recovery, the animals were handled daily and adapted to the procedure, i.e. they were connected to the EEG set-up and allowed to explore the Skinner box in which the recording would take place. In addition, the rats were adapted to per os (p.o.) administration procedures by saline injections $(2 \mathrm{ml} / \mathrm{kg})$. Next, the control condition was tested, i.e. animals were treated with placebo; this was tested twice and averaged for the statistical analysis. Subsequently three doses of the PDE5-I vardenafil were randomly tested $(0.3,1$ and $3 \mathrm{mg} / \mathrm{kg}$, p.o.). The sensory gating paradigm consisted of 70 pairs of auditory stimuli which were presented with stimulus duration of $10 \mathrm{~ms}$, ISI of $500 \mathrm{~ms}$ and ITI of 6-10 s. The EEG signal was sampled at 1,000 Hz, filtered between 1 and $133.5 \mathrm{~Hz}$ and stored on a personal computer. The stimuli were $2,500 \mathrm{~Hz}$ clicks with a sound intensity of $80 \mathrm{~dB}$. Since the animals were tested in a soundattenuated room with a maximal background noise level of $20 \mathrm{~dB}$, the level of our stimulus salience was approximately $60 \mathrm{~dB}$. After the study was finished, the animals were killed by decapitation and the brains were taken out. The brains were stored in $4 \%$ formaldehyde at $4-6{ }^{\circ} \mathrm{C}$ until electrode localisation took place.

\section{Treatment}

Vardenafil was first dissolved in $1.5 \mathrm{ml}$ ethanol with $2 \%$ Tween 80. After extraction of ethanol via vaporisation under $\mathrm{N} 2$ gas, the compounds were dissolved in $0.5 \%$ methylcellulose. The compound was tested at a dose of $0.3-3 \mathrm{mg} / \mathrm{kg}$ and administered by oral gavage $(2 \mathrm{ml} / \mathrm{kg}) 30 \mathrm{~min}$ before testing. Vardenafil was kindly donated by BAYER (Wuppertal, Germany). The experimenter was blind to the compound and doses tested. All animals were treated with each condition once, except for the control condition (placebo), which was tested twice as part of the training.

\section{Electrode localisation}

In order to verify the localisation of the striatal and hippocampal electrode, coronal slices $(50 \mu \mathrm{m})$ were made with a vibratome and put on glass slides. Next, a haematoxylin and eosin staining was applied and the slices were inspected under a microscope. If the localisation of the hippocampal or striatal electrode could not be verified and/or the raw data did not show the typical delta and theta waves in the hippocampal EEG, the animal was excluded for that part of the analyses (number of animals mentioned in the 'Results'). Since the vertex electrode measures the EEG signal at the cortical surface, there was no need for localisation.

\section{Statistical analysis}

Segments between $100 \mathrm{~ms}$ before until $500 \mathrm{~ms}$ after stimulus onset were made for each stimulus type (S1 and S2) separately, using the last $100 \mathrm{~ms}$ before onset as baseline. High- $(1 \mathrm{~Hz})$ and low-pass $(30 \mathrm{~Hz})$ filters were applied. The segments were visually checked and removed from the dataset if a movement artefact occurred within $500 \mathrm{~ms}$ after stimulus presentation. Both the grand average (all animals) and the individual data (single animal) were used to determine the auditory evoked potential (AEP) components. In general, $\mathrm{P} 1$ was defined as most positive value between 20 and $50 \mathrm{~ms}$ after stimulus onset. N1 was the most negative value between 50 and $80 \mathrm{~ms}$ for the vertex and between 40 and $70 \mathrm{~ms}$ for the striatum and hippocampus. Finally, P2 was defined as most positive value between 65 and $105 \mathrm{~ms}$ for the vertex and between 55 and $90 \mathrm{~ms}$ for the striatum and hippocampus.

General linear models (GLM) repeated measures were used to analyse the amplitudes of the components. First, the responses to the S1 and S2 were compared for the vehicle condition to see whether sensory gating occurred. Next, the responses to the PDE-Is conditions were compared with placebo condition for each stimulus (treatment) separately as well as for both stimuli together (treatment $\times$ stimulus). In case of a statistically reliable effect, comparisons between means of the conditions were analysed in more detail using post hoc Bonferroni $t$ tests $(P<0.05)$. Two animals were excluded from the analysis of the vertex and the striatum electrodes because of no reliable EEG signal.

\section{Human study}

\section{Subjects}

All experimental procedures were approved by the independent Ethics Committee of Maastricht University and the Academic Hospital Maastricht (The Netherlands). Eighteen participants ( $21 \pm 0.7$ years old; five males) were recruited through advertisements at Maastricht University. They had to be willing to sign an informed consent and were paid for their participation.

The subjects' physical and mental health was checked by a physician by means of a standard medical questionnaire and a medical examination. Subjects were 
excluded if they suffered from or had a history of cardiac, hepatic, renal, pulmonary, neurological, gastrointestinal, haematological or psychiatric illness. Other exclusion criteria were excessive drinking ( $>20$ glasses of alcohol containing beverages a week), pregnancy or lactation, use of medication other than oral contraceptives, use of recreational drugs from 2 weeks before until the end of the experiment and any sensory or motor deficit which could reasonably be expected to affect test performance. In addition, subjects who had a first-degree relative with (history of) a psychiatric disorder, were excluded as well. The participants could leave the study at any given time without any consequence.

\section{EEG recordings}

An EEG cap was used to place a set of 32 EEG electrodes according to the international 10-20 system (Jasper 1958). Only the Fz, Fcz and $\mathrm{Cz}$ locations were used in the current study since it has been demonstrated previously that midline electrodes show better P50 sensory gating than left/right hemispheric sites, especially the $\mathrm{Cz}$ (vertex) and Fcz electrodes (Wan et al. 2006). In addition, the $\mathrm{Fz}$ electrode has been demonstrated to show a similar amount of P200 gating and was therefore included as well (Wan et al. 2007). A reference and a ground were placed at the linked mastoids and at the forehead, respectively. Eye movements were detected by horizontal and vertical electro-oculogram (EOG) recordings. Before electrode attachment, the positions were cleaned with alcohol and slightly scrubbed with a gel in order to provide a good measurement. Both EEG and EOG were filtered between 0.01 and $100 \mathrm{~Hz}$ and sampled at 1,000 $\mathrm{Hz}$.

The sensory gating paradigm consisted of 60 pairs of identical auditory stimuli with a duration of $3 \mathrm{~ms}$ and intensity of $80 \mathrm{~dB}$. Since testing took place in a soundattenuated room with a maximal background noise level of $20 \mathrm{~dB}$, the stimulus salience was approximately $60 \mathrm{~dB}$. The interval between the first (S1) and the second (S2) stimulus was $500 \mathrm{~ms}$; the interval between pairs was randomised between 6 and $10 \mathrm{~s}$. The subjects were familiarised with this test during a training session.

\section{Design and treatment}

The study was conducted according to a double-blind, placebo-controlled, three-way cross-over design. Order of treatments was balanced over three test days and separated by a washout period of at least 7 days. The balancing of the treatment order was accomplished by counterbalancing.
Treatment consisted of a placebo, 10 or $20 \mathrm{mg}$ vardenafil $\mathrm{HCl}$ (Levitra) and was within the range of dosages (5-20 mg) approved for human use (EMEA 2008). Previous studies have shown that peak plasma levels of vardenafil were reached 30-120 min (median, $60 \mathrm{~min}$ ) after a single dose of $20 \mathrm{mg}$ vardenafil; the terminal half-life was around $4-5 \mathrm{~h}$ (EMEA 2008). Since this study was part of a larger experiment consisting of multiple tasks, our sensory gating paradigm was tested $85 \mathrm{~min}$ after drug treatment. The drugs were ingested orally and combined with a low-fat breakfast, because fatty food might affect the absorption of vardenafil. The experimenter and subjects were blind to the compound and doses tested.

\section{Medical questionnaire}

A medical questionnaire was presented to the subjects twice each testing day: directly before ingesting the compound/placebo (baseline) and approximately $100 \mathrm{~min}$ later (during a short break) (treatment). This questionnaire addressed 31 physical complaints, including headache, nausea, dry mouth, blurred vision and dizziness. Participants could indicate on a 4-point scale to what extent these items applied to their physical well-being $(0=$ not present; 3 =extremely present). The difference between the baseline and treatment scores were analysed by using GLM repeated measures.

\section{Statistical analysis}

Segments between $100 \mathrm{~ms}$ before until $500 \mathrm{~ms}$ after stimulus onset were made for each stimulus type (S1 and S2) separately, using the last $100 \mathrm{~ms}$ before onset as baseline. High-pass $(1 \mathrm{~Hz})$ and low-pass $(30 \mathrm{~Hz})$ filters were applied. The segments were visually checked for EOG activity and other artefacts and removed from the dataset if an artefact occurred during the first $500 \mathrm{~ms}$ after stimulus presentation. The grand average was used to determine the AEP components. P1 was defined as most positive value between 60 and $90 \mathrm{~ms}$ after stimulus onset, N1 as most negative value between 85 and $150 \mathrm{~ms}$ and $\mathrm{P} 2$ as most positive value between 140 and $250 \mathrm{~ms}$.

GLM repeated measures were used to analyse the amplitudes of the AEP components at the Fz, Fcz and $\mathrm{Cz}$ locations (channel). First, the responses to the $\mathrm{S} 1$ and S2 were compared for the placebo condition to see whether sensory gating occurred. Next, the responses to the vardenafil conditions were compared with the placebo condition for each stimulus separately (treatment $\times$ channel) as well as for both stimuli (treatment $\times$ stimulus $\times$ channel). In case of a statistically reliable effect, 
comparisons between means of the conditions were analysed in more detail using post hoc Bonferroni $t$ tests $(P<$ 0.05 ). One subject was excluded from the analyses because of an incomplete dataset.

\section{Results}

Animal study

\section{Effects of placebo on sensory gating in rats}

The effects of placebo treatment on sensory gating are depicted in Fig. 1. GLM repeated measures showed that the N1 peak is less negative in response to $\mathrm{S} 2$ than $\mathrm{S} 1$ at the vertex $\left(F_{1,10}=11.39 ; P<0.01\right)$. In the hippocampus, the $\mathrm{N} 1$ peak was also less negative after the presentation of $\mathrm{S} 2$ than $\mathrm{S} 1\left(F_{1,12}=6.20 ; P<0.05\right)$.

\section{Effects of PDE5 inhibition on information processing in rats}

No effects of vardenafil treatment $(0.3-3 \mathrm{mg} / \mathrm{kg}$ (p.o.) 30 min before testing) on the $\mathrm{P} 1, \mathrm{~N} 1$ and $\mathrm{P} 2$ were found in the hippocampus and striatum as well as for the $\mathrm{P} 1$ and $\mathrm{P} 2$ in the vertex. Vardenafil seemed to affect the $\mathrm{N} 1$ in the vertex $\left(F_{2.36}, 23.62=3.31 ; P<0.05\right)$, but further post hoc analysis revealed no difference between treatment conditions. This is illustrated in Fig. 2 showing the results of vardenafil treatment on the peaks and locations that showed sensory gating in the placebo condition (see Fig. 1) (N1 vertex - condition*stimulus $\left(F_{1.40,13.99}=0.33\right.$, n.s. $)$; hippocampus - condition*stimulus $\left(F_{1.90,22.81}=0.39\right.$, n.s. $)$, condition $\left(F_{1.97,23.69}=1.87\right.$, n.s. $\left.)\right)$.

Human study

\section{Effects of placebo on sensory gating in humans}

The effects of placebo treatment on sensory gating are depicted in Fig. 3. GLM repeated measures showed that there is an interaction between stimulus and channel for the P1 $\left(F_{1.08}, 17.22=4.60 ; P<0.05\right)$, N1 $\left(F_{1.21,19.36}=15.25\right.$; $P<0.001)$ and $\mathrm{P} 2\left(F_{1.21}, 19.39=24.61 ; P<0.001\right)$ peaks. Further analyses for the three channels separately showed that the $\mathrm{P} 1$ was less positive after S2 than $\mathrm{S} 1$ at the $\mathrm{Fcz}\left(F_{1,16}=\right.$ 5.69; $P<0.05)$ and $\mathrm{Cz}\left(F_{1,16}=7.13 ; P<0.05\right)$. In addition, the $\mathrm{N} 1$ was less negative and the $\mathrm{P} 2$ less positive after the $\mathrm{S} 2$ than $\mathrm{S} 1$ at the $\mathrm{Fz}\left(\mathrm{N} 1-F_{1}, 16=59.55 ; P<0.001 ; \mathrm{P} 2-F_{1}\right.$, $\left.{ }_{16}=34.94 ; P<0.001\right), \mathrm{Fcz}\left(\mathrm{N} 1-F_{1}, 16=56.32 ; P<0.001 ; \mathrm{P} 2\right.$ $\left.-F_{1,16}=50.08 ; P<0.001\right)$ and $\mathrm{Cz}\left(\mathrm{N} 1-F_{1,16}=49.48 ; P<\right.$ $\left.0.001 ; \mathrm{P} 2-F_{1,16}=52.73 ; P<0.001\right)$.

\section{Effects of PDE5 inhibition on information processing} in humans

The effect of vardenafil (10-20 mg (p.o.) $85 \mathrm{~min}$ before testing) administration on the ERP components in the placebo condition (see Fig. 3) are shown in Fig. 4.
Fig. 1 Effects of placebo (vehicle; p.o. 30 min before testing) on grand average ERPs (P1, N1 and P2 component) after the presentation of $\mathrm{S} 1$ and S2; effects on gating are depicted with asterisks $\left({ }^{*} P<\right.$ $0.05)$. Latencies are shown on the $x$-axis in milliseconds, amplitudes on the $y$-axis in microvolts. $n_{\text {vertex }}=11$;

$n_{\text {striatum }}=11 ; n_{\text {hippocampus }}=13$
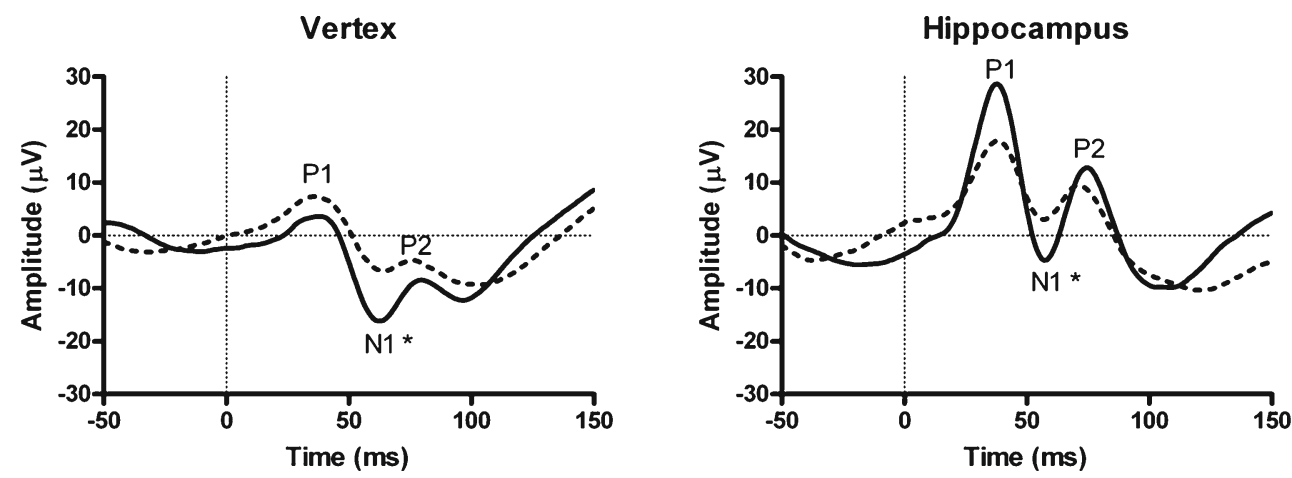

Striatum

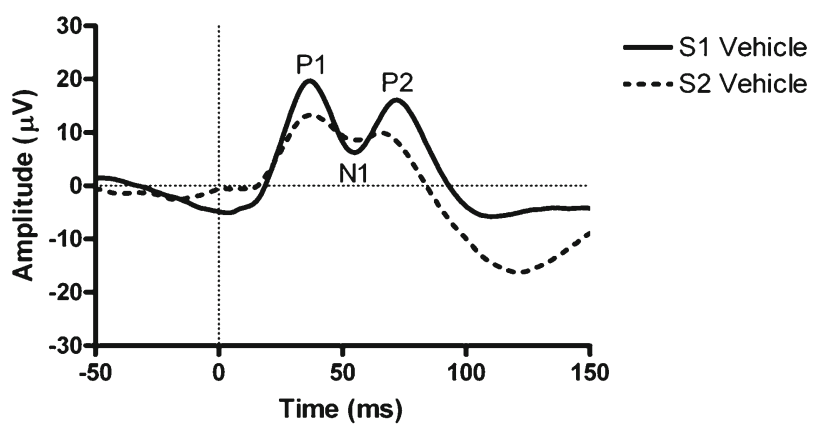


Fig. 2 No effects of treatment with the PDE5-I vardenafil on the mean amplitude $( \pm$ SEM) of $\mathrm{N} 1$ in the vertex and N1 in the hippocampus were found (GLM repeated measures). Drugs were given $30 \mathrm{~min}$ before testing. Compounds/doses are shown on the $x$-axis; amplitudes are presented on the $y$ axis in microvolts. $N_{\text {vertex }}=11$; $n_{\text {hippocampus }}=13$
N1 Vertex

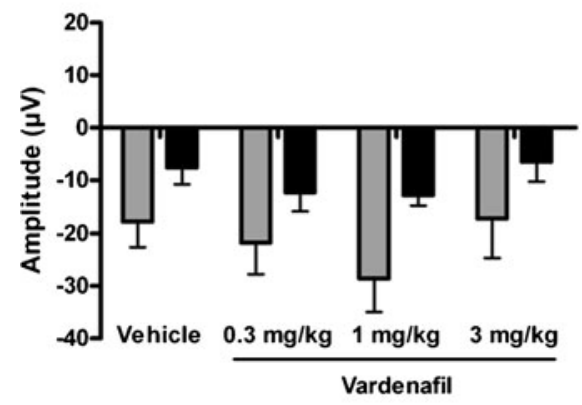

N1 Hippocampus

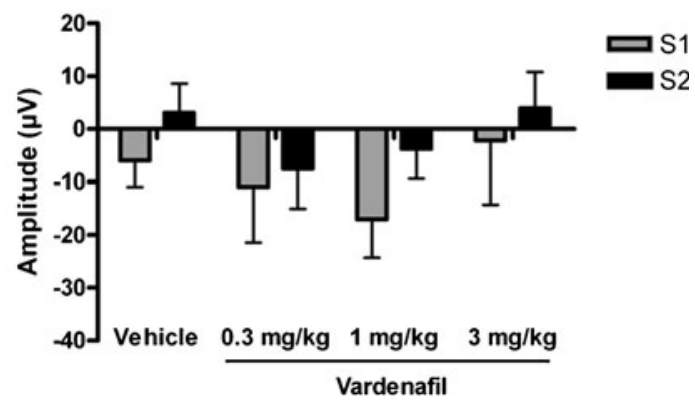

An interaction effect for the P1 was found for stimulus*treatment*channel $\left(F_{2.18}, 34.91=3.72 ; P<0.05\right)$. Additional analyses of the differences between S1 and S2 showed an interaction between treatment condition and channel $\left(F_{2.18}, 34.91=3.72 ; P<0.05\right)$. Post hoc analyses of each channel separately revealed no further effects. Furthermore, an interaction was detected for the N1 for stimulus*condition $\left(F_{1.43,22.86}=3.98 ; P<0.05\right)$; however, Bonferonni post hoc analysis of the difference between S1 and S2 showed no effect between treatment conditions. No effects of PDE5 inhibition on the P2 peak were found.

\section{Medical questionnaire}

An effect of treatment was found on the report of headache $\left(F_{1.76,28.10}=6.34 ; P<0.01\right)$ and feeling weak $\left(F_{1.63}, 26.00=7.43\right.$;
$P<0.01)$. Bonferroni post hoc analysis revealed that there was an increase after administration of both vardenafil 10 and $20 \mathrm{mg}$ compared with the placebo condition.

\section{Discussion}

The aim of this study was to test the effects of PDE5 inhibition on auditory sensory gating in rats and humans. It was demonstrated that after treatment with placebo the N1 in the vertex and the hippocampus was more negative after S1 than S2 in rats. Additionally, the response to the $\mathrm{S} 2$ was smaller than to the $\mathrm{S} 1$ at the $\mathrm{P} 1, \mathrm{~N} 1$ and $\mathrm{P} 2$ peak in humans in the placebo condition. This indicates that our paradigm elicited sensory gating in the rats as well as in the human subjects. However, neither in rats nor in humans an effect of PDE5 inhibition with vardenafil was found on sensory gating.
Fig. 3 Effects of placebo treatment (orally $85 \mathrm{~min}$ before testing) on grand average ERPs (P1, N1 and P2 component) after the presentation of $\mathrm{S} 1$ and $\mathrm{S} 2$; effects on gating are depicted with asterisks $(* P<0.05)(n=17)$. Latencies are shown on the $x$-axis in milliseconds, amplitudes on the $y$-axis in microvolts
Fz

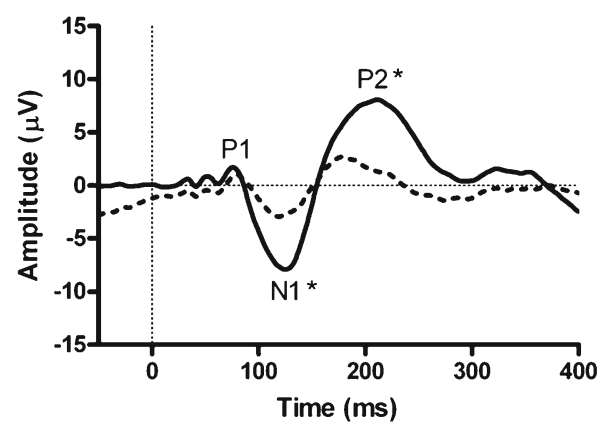

Fcz

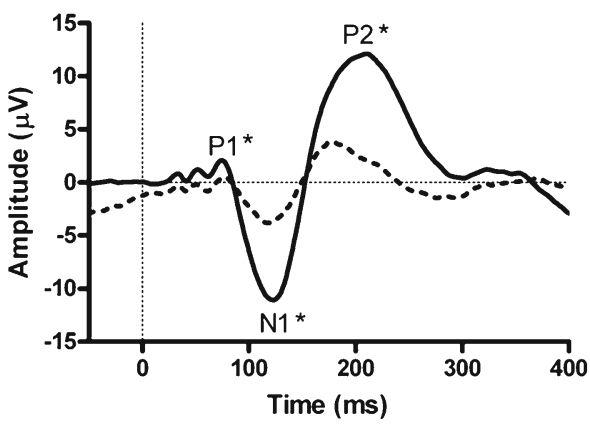

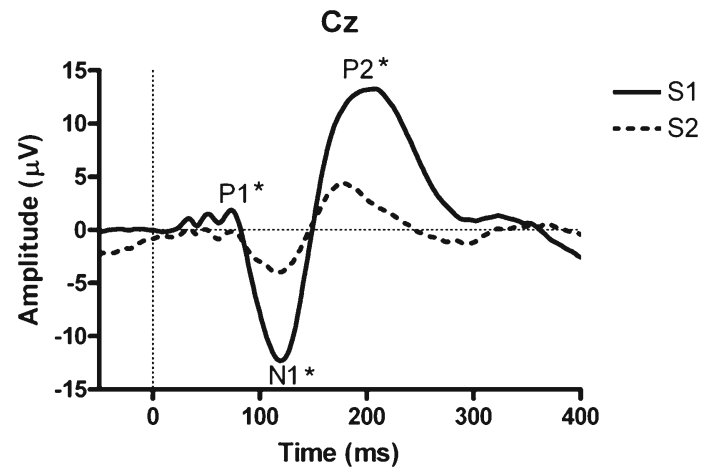


a

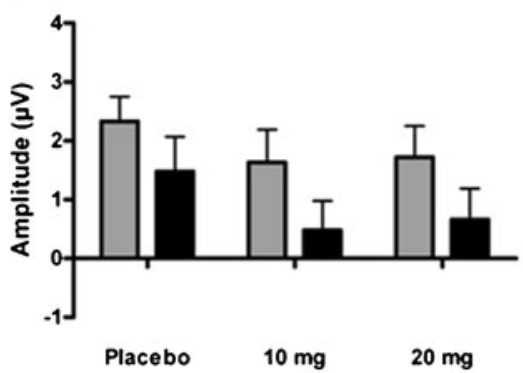

b

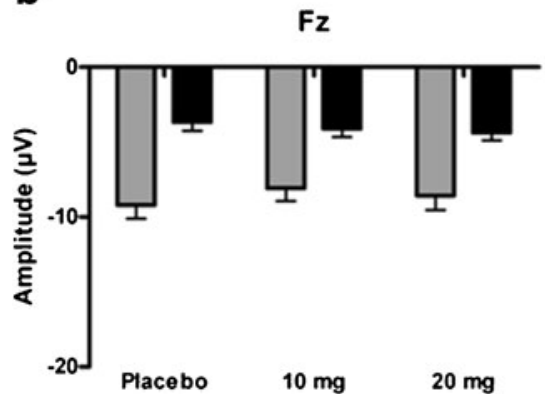

C

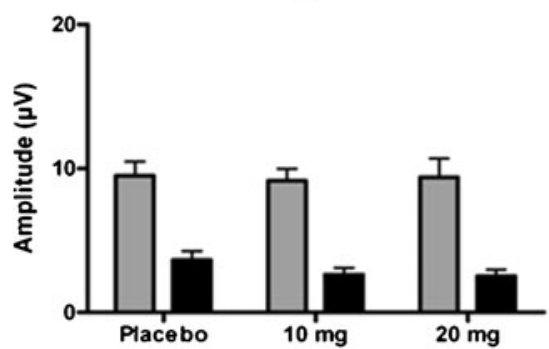

Fcz

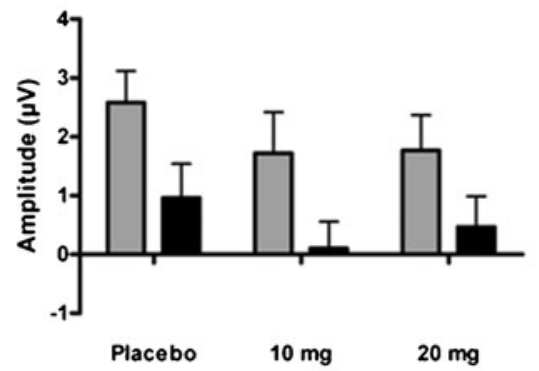

Fcz

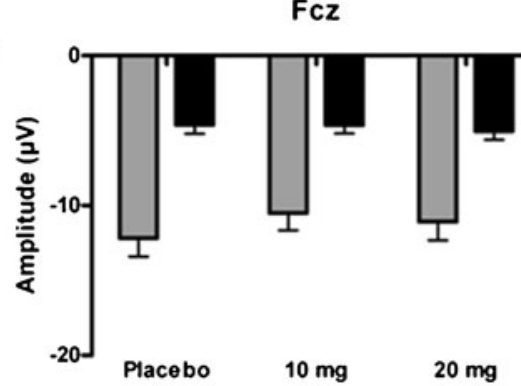

$\mathrm{Cz}$

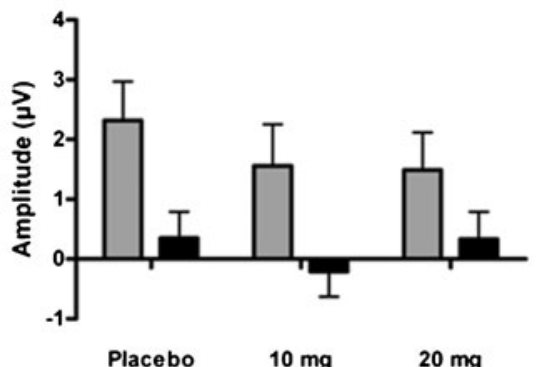

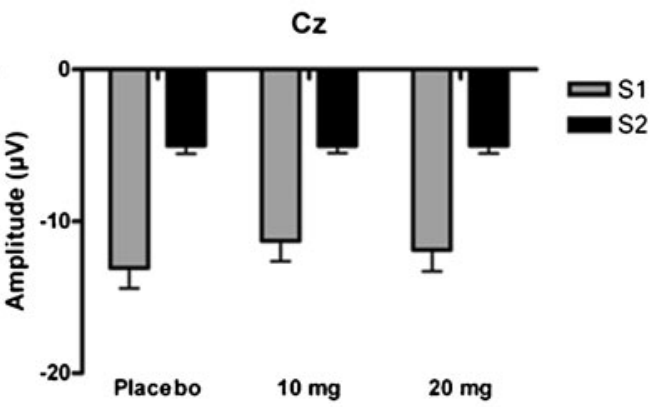
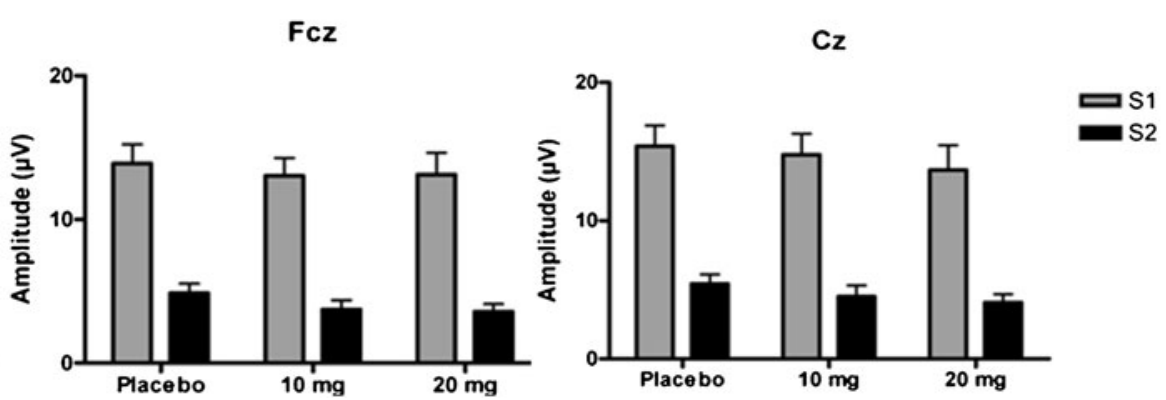

Fig. 4 No effects of treatment with the PDE5-I vardenafil on the mean amplitude $( \pm \mathrm{SEM})$ of $\mathbf{a} \mathrm{P} 1, \mathbf{b} \mathrm{N} 1$ and $\mathbf{c} \mathrm{P} 2$ after the presentation of $\mathrm{S} 1$ and S2 were found (GLM repeated measures). Drugs were given
85 min before testing; $n=17$. Compounds/doses are shown on the $x$ axis; amplitudes are presented on the $y$-axis in microvolts

calculated using vardenafil's molecular weight and its free fraction in plasma and brain homogenate. The free brain concentration of $3 \mathrm{mg} / \mathrm{kg}$ vardenafil was $0.4 \mathrm{nM}$, which is four times its $\mathrm{IC}_{50}$ value. This suggests that the 1 and $3 \mathrm{mg} / \mathrm{kg}$ doses of vardenafil used in the present study have sufficient biological activity, i.e. PDE5 inhibition. The dose of $0.3 \mathrm{mg} /$ $\mathrm{kg}$ vardenafil would have a relatively low biological activity of 0.4 times the $\mathrm{IC}_{50}$ but apparently still enough to be biologically active and to improve memory function as previously found in the object recognition task (Prickaerts et al. 2002a). It may thus be concluded that the doses of vardenafil we used in this study should have been expected to be active under the conditions tested.

As mentioned before, it has been shown that PDE5-Is improve cognition in a variety of behavioural tasks in rodents and monkeys (for overview, see Reneerkens et al. 2009). Yet, although the effects of PDE5 inhibition on cognition (especially learning and memory) have been 
widely investigated in rodents, little is known about the effects on EEG measurements, including ERPs. However, the results of our current study indicate that the positive effects of PDE5-Is in healthy adult rats might be mediated by affecting higher cognitive processes instead of early basic processes such as sensory gating.

Grass et al. (2001) studied the effects of sildenafil treatment on seven different psychophysical tasks measuring among others short-term memory and divided attention in healthy human subjects. Although PDE5 inhibition showed some effects in reaction time tests, no effects on the cognitive tasks were found. Interestingly, in a recent study of Shim et al. (2011) repeated dosing of the PDE5-I udenafil improved performance on the Korean version of the mini-mental state examination and an assessment battery addressing frontal executive functioning in patients suffering from erectile dysfunction. However, another study (Goff et al. 2009) investigating the effects of sildenafil administration in patients with schizophrenia did not show an effect on cognitive performance. The effects of sildenafil on positive and negative symptoms of schizophrenia were also investigated, but no changes in symptoms were found. In contrast, Akhandzadeh et al. (2011) demonstrated that sildenafil when combined with the atypical antipsychotic risperidone increased the latter's effectiveness in reducing the negative symptoms in patients with schizophrenia. Furthermore, it was shown in healthy subjects that although sildenafil treatment did not improve the behavioural response in attention and word recognition tasks, it did have an effect on EEG measurements (Schultheiss et al. 2001). During the auditory selective attention task, sildenafil elicited EEG responses indicative for an improvement of attention. No effects on ERP measurements related to word recognition were found, although a reduction in negativity of these measurements between 150 and $250 \mathrm{~ms}$ after stimulus presentation was found in the word recognition task. The role of this negative deflection in word recognition is not clear, but the authors suggest that 'there is an effect of sildenafil on cerebral information processing'. In our current study, we did not find an effect of PDE5 inhibition on a more specific part of information processing, namely sensory gating. However, the participants did report an increase in headache, which is one of the most commonly reported side effects $(\geq 10 \%$ of the subjects participating in clinical trials) after vardenafil treatment (EMEA 2008) and feeling weak after the administration of $10-20 \mathrm{mg}$ vardenafil compared with the placebo condition on a questionnaire about medical complaints. This indicates that vardenafil is at least bioactive at the dosages and time frame used in our sensory gating study. This would also be confirmed by previous pharmacokinetic data (EMEA 2008) which showed that the maximum plasma concentrations of vardenafil after oral dosing are reached within 30-120 min (median, $60 \mathrm{~min}$ ); our time point of testing after $85 \mathrm{~min}$ is well within this period when also side effects were reported. Additionally, when we take into account the body surface area and the body weight to extrapolate the animal dose to the human dose using the formula of Reagan-Shaw et al. (2008), the doses of $0.3-3 \mathrm{mg} / \mathrm{kg}$ in rats should be equivalent to $3-31 \mathrm{mg}$ in our human participants. This indicates that the 10 and $20 \mathrm{mg}$ dosages of vardenafil used in our human experiment are equivalent to the doses, i.e. higher than $1 \mathrm{mg} / \mathrm{kg}$, which have been shown to exert positive effects on $\operatorname{cog}$ nition in previous animal studies (e.g. Prickaerts et al. 2002b; Reneerkens et al. 2012) and which we also used in the present animal experiment. Thus, although we did not find an effect of vardenafil on sensory gating, the compound can be assumed to be bioactive. So, the effects of PDE5-Is on EEG measures seem to be task dependent and might affect different parts of information processing as we used a sensory gating paradigm to measure the effects on basic auditory information processing, whereas Schultheiss et al. (2001) found the effect in a word recognition task after treatment with $100 \mathrm{mg}$ sildenafil. It cannot be ruled out completely that stimulus salience might have had an effect on the ability to detect drug effects as well since there are sensory gating studies in which the stimuli did not exceed 15-20 dB above background noise levels in animals (Halene and Siegel 2008) and humans (Cadenhead et al. 2005). However, based on previous experiments in our lab (e.g. Sambeth et al. 2007) and a wide variety of sensory gating studies in animals (e.g. Mears et al. 2006; Sambeth et al. 2003; Zhou et al. 2008) as well as humans (Dalecki et al. 2011; Jessen et al. 2001; Lijffijt et al. 2009) which used stimulus parameters similar to ours, it is unlikely that stimulus salience affected our results.

To summarise, the PDE5-I vardenafil did not affect basic auditory information processing tested in a sensory gating paradigm in rats or humans. These findings imply that the positive effects of PDE5 inhibition previously found in both species are possibly the result of positive effects on higher cognitive functions specifically (e.g. memory or attention) instead of on more basic processes involved in a variety of cognitive domains (e.g. basic auditory processing). To further elucidate the effects of PDE5 inhibition on cognition, identical deficit models in animals and humans (e.g. scopolamine or ketamine) should be used in a translational setting. In addition, testing the effects of PDE5-Is on cognitive performance and EEG measurements in a patient population suffering from cognitive dysfunction (e.g. patients with schizophrenia and patients suffering from dementia) is likely to provide further insight into the cognition-enhancing potential of PDE5 inhibition. 
Conflicts of interest None

\section{References}

Adler LE, Pachtman E, Franks RD, Pecevich M, Waldo MC, Freedman R (1982) Neurophysiological evidence for a defect in neuronal mechanisms involved in sensory gating in schizophrenia. Biol Psychiatry 17:639-654

Akhondzadeh S, Ghayyoumi R, Rezaei F, Salehi B, Modabbernia AH, Maroufi A, Esfandiari GR, Naderi M, Ghebleh F, Tabrizi M, Rezazadeh SA (2011) Sildenafil adjunctive therapy to risperidone in the treatment of the negative symptoms of schizophrenia: a double-blind randomized placebo-controlled trial. Psychopharmacol (Berl) 213:809-815

Ally BA, Jones GE, Cole JA, Budson AE (2006) Sensory gating in patients with Alzheimer's disease and their biological children. Am J Alzheimers Dis Other Demen 21:439-447

Bender AT, Beavo JA (2006) Cyclic nucleotide phosphodiesterases: molecular regulation to clinical use. Pharmacol Rev 58:488-520

Boutros NN, Brockhaus-Dumke A, Gjini K, Vedeniapin A, Elfakhani M, Burroughs S, Keshavan M (2009) Sensory-gating deficit of the N100 mid-latency auditory evoked potential in medicated schizophrenia patients. Schizophr Res 113:339-346

Broberg BV, Oranje B, Glenthoj BY, Fejgin K, Plath N, Bastlund JF (2010) Assessment of auditory sensory processing in a neurodevelopmental animal model of schizophrenia-gating of auditory-evoked potentials and prepulse inhibition. Behav Brain Res 213:142-147

Cadenhead KS, Light GA, Shafer KM, Braff DL (2005) P50 suppression in individuals at risk for schizophrenia: the convergence of clinical, familial, and vulnerability marker risk assessment. Biol Psychiatry 57:1504-1509

Chang WP, Arfken CL, Sangal MP, Boutros NN (2011) Probing the relative contribution of the first and second responses to sensory gating indices: a meta-analysis. Psychophysiology 48:980-992

Cromwell HC, Mears RP, Wan L, Boutros NN (2008) Sensory gating: a translational effort from basic to clinical science. Clin EEG Neurosci 39:69-72

Dalecki A, Croft RJ, Johnstone SJ (2011) An evaluation of P50 pairedclick methodologies. Psychophysiology 48:1692-1700

Devan BD, Bowker JL, Duffy KB, Bharati IS, Jimenez M, Sierra-Mercado D Jr, Nelson CM, Spangler EL, Ingram DK (2006) Phosphodiesterase inhibition by sildenafil citrate attenuates a maze learning impairment in rats induced by nitric oxide synthase inhibition. Psychopharmacol (Berl) 183:439-445

Devan BD, Pistell PJ, Daffin LW Jr, Nelson CM, Duffy KB, Bowker JL, Bharati IS, Sierra-Mercado D, Spangler EL, Ingram DK (2007) Sildenafil citrate attenuates a complex maze impairment induced by intracerebroventricular infusion of the NOS inhibitor $N$ (omega)-nitro-L-arginine methyl ester. Eur J Pharmacol 563:134-140

EMEA (2008) European Public Assessment Report; revision 6. Available from www.emea.europa.eu

Goff DC, Cather C, Freudenreich O, Henderson DC, Evins AE, Culhane MA, Walsh JP (2009) A placebo-controlled study of sildenafil effects on cognition in schizophrenia. Psychopharmacol (Berl) 202:411-417

Grass H, Klotz T, Fathian-Sabet B, Berghaus G, Engelmann U, Kaferstein H (2001) Sildenafil (Viagra): is there an influence on psychological performance? Int Urol Nephrol 32:409-412

Hajos M (2006) Targeting information-processing deficit in schizophrenia: a novel approach to psychotherapeutic drug discovery. Trends Pharmacol Sci 27:391-398
Halene TB, Siegel SJ (2008) Antipsychotic-like properties of PDE4 inhibitors - evaluation of RO-20-1724 with auditory event related potentials and prepulse inhibition of startle. J Pharmacol Exp Ther 326:230-239

Hitchcock SA, Pennington LD (2006) Structure-brain exposure relationships. J Med Chem 49:7559-7583

Jasper H (1958) The ten-twenty electrode system of the international federation. Electroencephalogr Clin Neurophysiol 10:371-375

Javitt DC (2009) Sensory processing in schizophrenia: neither simple nor intact. Schizophr Bull 35:1059-1064

Jessen F, Kucharski C, Fries T, Papassotiropoulos A, Hoenig K, Maier W, Heun R (2001) Sensory gating deficit expressed by a disturbed suppression of the P50 event-related potential in patients with Alzheimer's disease. Am J Psychiatry 158:1319-1321

Lijffijt M, Moeller FG, Boutros NN, Burroughs S, Lane SD, Steinberg JL, Swann AC (2009) The role of age, gender, education, and intelligence in P50, N100, and P200 auditory sensory gating. J Psychophysiol 23:52-62

Maxwell CR, Liang Y, Weightman BD, Kanes SJ, Abel T, Gur RE, Turetsky BI, Bilker WB, Lenox RH, Siegel SJ (2004) Effects of chronic olanzapine and haloperidol differ on the mouse N1 auditory evoked potential. Neuropsychopharmacology 29:739-746

Mears RP, Klein AC, Cromwell HC (2006) Auditory inhibitory gating in medial prefrontal cortex: single unit and local field potential analysis. Neuroscience 141:47-65

Mears RP, Boutros NN, Cromwell HC (2009) Reduction of prelimbic inhibitory gating of auditory evoked potentials after fear conditioning. Behav Neurosci 123:315-327

Miyazato H, Skinner RD, Garcia-Rill E (1999) Neurochemical modulation of the P13 midlatency auditory evoked potential in the rat. Neuroscience 92:911-920

Paxinos G, Watson C (1998) The rat brain in stereotaxic coordinates, 4 th edn. Academic, New York

Prickaerts J, de Vente J, Honig W, Steinbusch HW, Blokland A (2002a) cGMP, but not cAMP, in rat hippocampus is involved in early stages of object memory consolidation. Eur J Pharmacol 436:8387

Prickaerts J, van Staveren WC, Sik A, Markerink-van Ittersum M, Niewohner U, van der Staay FJ, Blokland A, de Vente J (2002b) Effects of two selective phosphodiesterase type 5 inhibitors, sildenafil and vardenafil, on object recognition memory and hippocampal cyclic GMP levels in the rat. Neuroscience 113:351-361

Prickaerts J, Sik A, van Staveren WC, Koopmans G, Steinbusch HW, van der Staay FJ, de Vente J, Blokland A (2004) Phosphodiesterase type 5 inhibition improves early memory consolidation of object information. Neurochem Int 45:915-928

Reagan-Shaw S, Nihal M, Ahmad N (2008) Dose translation from animal to human studies revisited. FASEB J 22:659-661

Reneerkens OA, Rutten K, Steinbusch HW, Blokland A, Prickaerts J (2009) Selective phosphodiesterase inhibitors: a promising target for cognition enhancement. Psychopharmacol (Berl) 202:419 443

Reneerkens OA, Rutten K, Akkerman S, Blokland A, Shaffer CL, Menniti FS, Steinbusch HW, Prickaerts J (2012) Phosphodiesterase type 5 (PDE5) inhibition improves object recognition memory: indications for central and peripheral mechanisms. Neurobiol Learn Mem 97:370-379

Rutten K, Prickaerts J, Hendrix M, van der Staay FJ, Sik A, Blokland A (2007) Time-dependent involvement of cAMP and cGMP in consolidation of object memory: studies using selective phosphodiesterase type 2, 4 and 5 inhibitors. Eur J Pharmacol 558:107112

Rutten K, Basile JL, Prickaerts J, Blokland A, Vivian JA (2008) Selective PDE inhibitors rolipram and sildenafil improve object retrieval performance in adult cynomolgus macaques. Psychopharmacol (Berl) 196:643-648 
Rutten K, Van Donkelaar EL, Ferrington L, Blokland A, Bollen E, Steinbusch HW, Kelly PA, Prickaerts JH (2009) Phosphodiesterase inhibitors enhance object memory independent of cerebral blood flow and glucose utilization in rats. Neuropsychopharmacology 34:1914-1925

Sambeth A, Maes JH, Van Luijtelaar G, Molenkamp IB, Jongsma ML, Van Rijn CM (2003) Auditory event-related potentials in humans and rats: effects of task manipulation. Psychophysiology 40:60 68

Sambeth A, Riedel WJ, Smits LT, Blokland A (2007) Cholinergic drugs affect novel object recognition in rats: relation with hippocampal EEG? Eur J Pharmacol 572:151-159

Schultheiss D, Muller SV, Nager W, Stief CG, Schlote N, Jonas U, Asvestis C, Johannes S, Munte TF (2001) Central effects of sildenafil (Viagra) on auditory selective attention and verbal recognition memory in humans: a study with event-related brain potentials. World J Urol 19:46-50
Shim YS, Pae CU, Kim SW, Kim HW, Kim JC, Koh JS (2011) Effects of repeated dosing with udenafil (Zydena) on cognition, somatization and erection in patients with erectile dysfunction: a pilot study. Int J Impot Res 23:109-114

van Donkelaar EL, Rutten K, Blokland A, Akkerman S, Steinbusch HW, Prickaerts J (2008) Phosphodiesterase 2 and 5 inhibition attenuates the object memory deficit induced by acute tryptophan depletion. Eur J Pharmacol 600:98-104

Wan L, Crawford HJ, Boutros N (2006) P50 sensory gating: impact of high vs. low schizotypal personality and smoking status. Int $\mathrm{J}$ Psychophysiol 60:1-9

Wan L, Crawford HJ, Boutros N (2007) Early and late auditory sensory gating: moderating influences from schizotypal personality, tobacco smoking status, and acute smoking. Psychiatry Res 151:11-20

Zhou D, Ma Y, Liu N, Chen L, He M, Miao Y (2008) Influence of physical parameters of sound on the sensory gating effects of N40 in rats. Neurosci Lett 432:100-104 